\title{
Neutrophil-derived cytokines: facts beyond expression
}

\author{
Cristina Tecchio $^{1}{ }^{*}$, Alessandra Micheletti $^{2}$ and Marco A. Cassatella ${ }^{2}$ * \\ Section of Hematology, Department of Medicine, School of Medicine, University of Verona, Verona, Italy \\ 2 Section of General Pathology, Department of Pathology and Diagnostics, School of Medicine, University of Verona, Verona, Italy
}

Edited by:

Paige Lacy, University of Alberta,

Canada

\section{Reviewed by:}

Eric Denkers, Cornell University, USA

Abhishek D. Garg, Katholieke

Universiteit Leuven, Belgium

*Correspondence:

Cristina Tecchio, Section of

Hematology, Department of

Medicine, Piazzale L. A. Scuro, Verona

37134, Italy

e-mail: cristina.tecchio@univr.it;

Marco A. Cassatella, Section of

General Pathology, Department of

Pathology and Diagnostics, Strada Le

Grazie 8, Verona 37134, Italy

e-mail:marco.cassatella@univr.it
Polymorphonuclear neutrophils, besides their involvement in primary defense against infections - mainly through phagocytosis, generation of toxic molecules, release of enzymes, and formation of extracellular traps - are also becoming increasingly important for their contribution to the fine regulation in development of inflammatory and immune responses. These latter functions of neutrophils occur, in part, via their de novo production and release of a large variety of cytokines, including chemotactic cytokines (chemokines). Accordingly, the improvement in technologies for molecular and functional cell analysis, along with concomitant advances in cell purification techniques, have allowed the identification of a continuously growing list of neutrophil-derived cytokines, as well as the characterization of their biological implications in vitro and/or in vivo. This short review summarizes crucial concepts regarding the modalities of expression, release, and regulation of neutrophil-derived cytokines. It also highlights examples illustrating the potential implications of neutrophilderived cytokines according to recent observations made in humans and/or in experimental animal models.

Keywords: neutrophil, cytokine, chemokine, human, mouse

\section{INTRODUCTION}

The immune system is well suited to a quick and specific response against foreign invaders, its ultimate objective being to protect an organism from injury and disease. Cytokines represent an integral component of the signaling networks among various cells, being, for instance, essential for the development and regulation of innate and adaptive immune processes. Cytokines constitute a large family of small proteins that are produced by immune and non-immune cells and that act locally among neighboring cells to direct important biological processes such as inflammation, immunity, repair, and angiogenesis (1). In this context, the relatively recent acquisition that also activated neutrophils, among leukocytes, are able to express and release a number of cytokines (2) has convinced researchers in the field to reconsider and thus reinvestigate neutrophil biological role not only in the context of inflammatory processes, but also in other conditions $(3-5)$. By doing so, it has clearly emerged that, given the large array of cytokines that may potentially be produced (Figure 1),

Abbreviations: APRIL, a proliferation inducing ligand; BAFF, B-cell activating factor; BNDF, brain-derived neurotrophic factor; Bv8, bombina variegata peptide 8; HB-EGF, heparin-binding endothelial growth factor, (EGF)-like growth factor; FGF2, fibroblast growth factor-2; G-CSF, granulocyte colony-stimulating factor; GM-CSF, granulocyte/macrophage-colony-stimulating factor; HGF, hepatocyte growth factor; IL1-ra, interleukin 1 receptor antagonist; LIGHT, lymphotoxinrelated inducible ligand that competes for glycoprotein D binding to HVEM on T cells; M-CSF, macrophage-colony-stimulating factor; MIF, macrophage migration inhibitory factor; MIP2, macrophage inflammatory protein 2; NGF, nerve growth factor; NT4, neurotrophin 4; PBEF, pre-B-cell colony enhancing factor; RANKL, receptor activator of nuclear factor kappa-B (NFKB) ligand; SCF, stem cell factor; TGF $\alpha$, transforming growth factor alpha; TGF $\beta$, transforming growth factor beta; TRAIL, TNF-related apoptosis-inducing ligand; TSLP, thymic stromal lymphopoietin; VEGF, vascular endothelial growth factor. neutrophils can be functionally involved either in physiological processes such as hematopoiesis, angiogenesis, and wound healing $(2,6)$, or in pathological processes including inflammatory, infectious, autoimmune, and neoplastic diseases $(2,4,7,8)$. Needless to say that, based on the afore-mentioned considerations, there is an increasing interest in clearly identifying and characterizing all the cytokines that neutrophils may produce, as well as their precise role in diseases, with the purpose of identifying novel targets for therapeutic interventions.

\section{CYTOKINE EXPRESSION IN NEUTROPHILS: TOOLS AND CAVEATS}

Our knowledge of the production of cytokines by neutrophils mostly derives from studies on humans and mice. Human neutrophils are usually isolated from the peripheral blood, while murine neutrophils are traditionally isolated from the bone marrow or the peritoneal cavity. Similarly to other cell types, also in neutrophils the production of cytokines is usually preceded by an increased accumulation of the related mRNA transcripts, which can be detected by techniques such as quantitative reversetranscription polymerase chain reaction ( $\mathrm{qPCR}$ ), Northern Blotting, ribonuclease protection assay, and in situ hybridization (9). The fact that, per-cell, neutrophils possess 10-20 times less RNA than other leukocytes (10), illustrates the need for using rigorous isolation procedures to allow the recovery of highly purified cell populations. In fact, a mononuclear cell contamination of neutrophils equal to only $1 \%$ (or even less) can translate into up to 20 $30 \%$ RNA contamination (9): the latter, depending on the expression levels of the cytokine mRNA under study, may obviously produce false positive results attributed to neutrophils. Nowadays, reliable tools guaranteeing the isolation of highly purified $\mathrm{CD} 6 \mathrm{~b}^{+} / \mathrm{C} 11 \mathrm{~b}^{+} / \mathrm{CD} 16^{-}$neutrophils (e.g., by immunomagnetic 


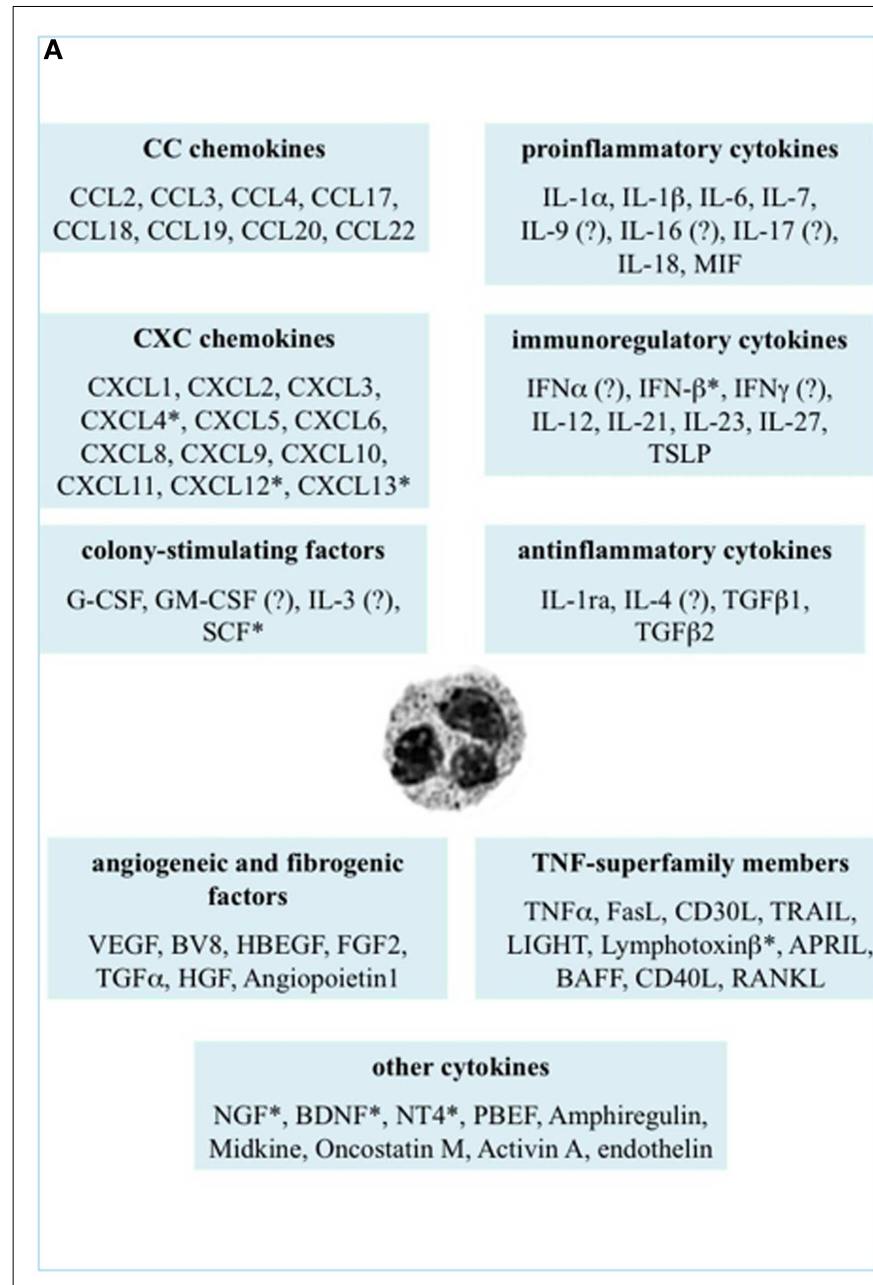

FIGURE 1 | Cytokines that neutrophils can potentially express and/or produce. Expression and/or production of the listed cytokines have been validated in human (A) and murine (B) neutrophils by gene expression

\section{B}

$\begin{array}{cc}\text { CC chemokines } & \text { proinflammatory cytokines } \\ \text { CCL2, CCL3, CCL4, CCL5, } & \text { IL-1 } \alpha, \text { IL-1 } \beta, \text { IL-6, IL-17, IL-18, } \\ \text { CCL17, CCL19(?), CCL20 } & \text { MIF } \\ \text { CXC chemokines } & \text { immunoregulatory cytokines } \\ \begin{array}{c}\text { CXCL1, CXCL2, CXCL4*, } \\ \text { CXIP2, CXCL9, CXCL10, }\end{array} & \text { IFN } \beta \text {, IFN } \gamma \text {, IL-10, IL-12, IL-21, } \\ \text { IL-22, IL-23 } \\ \text { colony-stimulating factors } \\ \text { G-CSF, M-CSF }\end{array}$

techniques, immunohistochemistry, enzyme-linked immunoadsorbent assays (ELISAs), or biological assays. ${ }^{*}$ Refers to studies performed at the mRNA level only. ? Indicates controversial data. negative selection) are commercially available $(11,12)$. Even in mice, cytokine production by neutrophils should be carefully reevaluated by utilizing $\mathrm{Ly} 6 \mathrm{G}^{\text {high }} / \mathrm{CD} 11 \mathrm{~b}^{\text {high }}$ positive cells only, as recently done (13).

It is also important to mention that, at least in vitro and with few exceptions, neutrophils usually make fewer molecules of a given cytokine than monocytes/macrophages or lymphocytes do on a per-cell basis $(2,10)$. In vivo, however, neutrophils constitute the majority of infiltrating cells in inflamed tissues and often outnumber mononuclear leukocytes by one to two orders of magnitude. Thus, the fact that neutrophils clearly predominate over other cell types under various in vivo conditions suggests that, under those circumstances, the contribution of neutrophil-derived cytokines can be of foremost importance. In any case, neutrophilderived cytokines can be measured in cell-free supernatants or in cell lysates by using various methods, including enzyme-linked immunoadsorbent assays, radioimmunoassays, immunoprecipitation after metabolic labeling, bioassays, immunohistochemistry, intracellular staining by flow cytometry, or confocal microscopy.
In our opinion, the latter two techniques should be used only to support other methods, due to potential artifacts consequent to antibody cross-reactivity or elevated neutrophil autofluorescence. Another important caveat for in vitro studies regards the necessity to always use endotoxin-free tissue culture media or reagents, since neutrophils respond to picomolar concentrations of lipopolysaccharide (LPS) $(2,10)$.

The literature demonstrates that neutrophils express and produce cytokines either constitutively or upon activation by microenvironmental stimuli (2). A variety of neutrophil receptors, including colony-stimulating factor and cytokine receptors, G protein coupled-, Fc $\gamma$ - and complement receptors, or many pattern recognition receptors (PRR) (germline-encoded receptors recognizing structures in microorganisms and tissue damage products), have been shown to trigger cytokine production in neutrophils $(2,14)$. Among PRR, human and mice neutrophils are known to express almost all Toll-like receptors (TLRs), as well as to respond to their ligands [(15), and references therein]. TLR3 and TLR7 are actually the only TLRs that human neutrophils 
do not express (16-18), unlike murine neutrophils that instead accumulate significantly high levels of TLR7 mRNA under inflammatory conditions $(19,20)$. Moreover, murine neutrophils do not basally express TLR3 transcripts $(16,21,22)$ even though eventual accumulation has never been quantified under inflammatory condition. Interestingly, in human neutrophils, TLR4 activation by LPS fails to directly trigger the production of type I INFs and type I IFN-dependent genes as in other cell types $(23,24)$, due to its inability to engage the so called "TIR domain-containing adaptor protein inducing interferon $\beta$ (TRIF)/TRIF-related adaptor molecule (TRAM)"-dependent pathway $(23,24)$.

Finally, an increasing number of studies have documented that TLR-induced cytokine expression by neutrophils can be positively/negatively influenced by immunomodulating factors such as $\operatorname{IFN} \gamma(25,26)$ and IL-10 $(27)$, respectively.

Following stimulation, neutrophils control their cytokine expression and production patterns by utilizing fine regulatory mechanisms acting at the transcriptional and/or posttranscriptional level $(2,4,7,28)$. Interestingly, recent studies have demonstrated that also microRNAs may regulate cytokine and chemokine production in neutrophils. For instance, miR9 was for the first time demonstrated to inhibit NFKB1/p50 transcripts in human neutrophils exposed to pro-inflammatory signals, operating in this manner as a feedback control for NFKB1/p50dependent responses (29). More recently, miR-223 has been shown to negatively control the production of CXCL2, CCL3, and IL-6 by neutrophils, in a mouse model of Mycobacterium tuberculosis infection (30). These latter data have contributed in shedding light on the hitherto controversial role of neutrophils in tuberculosis (31), as they suggest that miR-223-dependent inhibitory effects may negatively control leukocyte chemotaxis at late stages of lung inflammation by means of developmentally accumulated miR223 (30). Interestingly, examples of de novo synthesized cytokines that neutrophils store in significant amounts within intracellular pools also exist, and include B-cell activating factor (BAFF), TNF-related apoptosis-inducing ligand (TRAIL), CXCL8, CCL20, and interleukin (IL) 1 receptor antagonist (IL1-ra) $(32,33)$. However, very little is known on the precise intracellular localization and trafficking of these various cytokines and chemokines. Thus, much more work is needed to understand if, and how, the various neutrophil granules or other intracellular organelles contribute to cytokine metabolism and release (34).

\section{CYTOKINE PRODUCTION BY NEUTROPHILS: FACTS}

Figure 1 displays the cytokines that, to date, have been shown to be expressed or produced by, respectively, human (panel A) and murine (panel B) neutrophils, either constitutively or upon stimulation. It is evident that neutrophils express/produce cytokines belonging to various families, mostly including pro-inflammatory/anti-inflammatory cytokines, chemokines, immunoregulatory cytokines, tumor necrosis factor (TNF) superfamily members, and angiogenic/fibrogenic factors. At first sight, an analysis of the figure immediately suggests that the ability of neutrophils to produce such a variety of cytokines enables them to significantly influence not only the multiple aspects of the inflammatory and immune responses, but also antiviral defense, hematopoiesis, angiogenesis, and fibrogenesis.
Importantly, numerous in vivo observations have confirmed and reproduced the in vitro findings, as well as often clarifying their biological meanings and implications (2). It can also be noticed that, in spite of a substantial conservation between the human and murine genomes (35), some differences in cytokine production exist between the two species (Figure 1), thus warning toward a sic et simpliciter extrapolation of data from experimental systems in animals to humans, or vice versa. In the case of IL-10, for instance, basal differences in the chromatin status of the $I L-10$ locus, rather than a different responsiveness to activating signals, have been shown to account for the differential ability of human and murine neutrophils to switch on transcription of the IL-10 gene (36).

In the following paragraphs, some up-to-date findings illustrating potential biological roles that neutrophil-derived chemokines, pro-inflammatory/immunoregulatory cytokines, and TNF-superfamily members might have, under pathophysiological contexts, are briefly mentioned. For an extensive description on the role of neutrophil-derived cytokines in cancer and in angiogenesis, the reader may refer to our recent reviews $(6,8)$.

\section{CHEMOKINES}

Chemokines, amongst the cytokines produced by neutrophils, are of particular relevance because of their singular ability to selectively recruit discrete cell populations into sites of injury and thereby effectively regulate leukocyte trafficking (37). In addition, chemokines play fundamental roles in coordinating immune system responses, in regulating B- and T-cell development and in modulating angiogenesis (38). As displayed in Figure 1, both human and murine neutrophils may potentially produce several chemokines upon activation, including IL-8/CXCL8, GRO $\alpha / C X C L 1$, MIG/CXCL9, IP-10/CXCL10, and ITAC/CXCL11, monocyte chemotactic protein-1 (MCP-1/CCL2), macrophage inflammatory protein- $1 \alpha$ (MIP-1 $\alpha /$ CCL3) and MIP$1 \beta /$ CCL4 (37). Because the chemokines produced by neutrophils are primarily chemotactic for neutrophils, monocytes, dendritic cells (DCs), natural killer (NK) cells, and T-helper type 1 (Th1) and type 17 (Th17) cells, a potential role for neutrophils in amplifying their own arrival (39), as well as in orchestrating the sequential recruitment to, and activation of, distinct leukocyte types in the inflamed tissue, is plausible $(37,40)$. And in fact, in in vitro experiments, it has been demonstrated that: (i) human neutrophils activated by neutrophil-activating protein A from Borrelia burgdorferi recruit IFN $\gamma$ - and IL-17-producing T lymphocytes via CCL2, CCL20, and CXCL10 release (41); (ii) LPSactivated neutrophils induce chemotaxis of immature and mature DCs, as well as adhesion of CCR6- and CCR7-expressing T cells via CCL19 and CCL20 (42); and (iii) IFN $\gamma$ plus LPS-activated neutrophils induce chemotaxis of Th17 cells through CCL2 and CCL20 (11). Moreover, in different mouse models it has been proved that: (i) DCs are recruited to the Leishmania inoculation site by neutrophil-derived CCL3 (43); (ii) immature DCs are strongly attracted by neutrophil-derived CCL3, CCL4, CCL5, and CCL20 triggered by Toxoplasma gondii (44); and (iii) macrophage influx to granulomas is dependent on CCL3 and CCL4 released by activated neutrophils (45). More recently, CCL17, a chemokine that binds to CCR4, a chemokine receptor expressed in T-helper type 2 (Th2) cells and in regulatory T cells (Tregs) (46), has been 
added to the list of neutrophil-derived chemokines $(47,48)$. Consistently, tumor-associated neutrophils (TANs) have been shown to chemoattractants Tregs in a mouse model of cancer, mainly via CCL17 (49). Because neutrophil depletion, in this model, was shown to reduce Tregs recruitment and, consequently, tumor growth, data provide, for the first time, a clear link between TANs and Tregs, acting together to impair antitumor immunity (49).

\section{PRO-INFLAMMATORY AND IMMUNOREGULATORY CYTOKINES}

As shown in Figure 1, neutrophils may become a significant source of pro-inflammatory and/or immunoregulatory cytokines. Among these cytokines, recent research has focused on neutrophilderived IL-17 and IFN $\gamma$, as well as on their eventual role in inflammatory diseases and/or in protection against infections. However, since the data on the effective capacity of human neutrophils to express/produce IL-17 $(11,50)$ or $\operatorname{IFN} \gamma(51,52)$ are still controversial in literature, we can only report on studies carried out in mice.

For instance, IL-23- and, indirectly, IL-12-, activated Gr-1 ${ }^{+}$. neutrophils, but not Th17 cells, have been found to be the predominant source of IL-17A in a mouse model of kidney ischemiareperfusion injury (IRI) (53). Such neutrophil-derived IL-17 has been then shown to regulate natural killer T cells (NKT) activation, IFN $\gamma$ production, neutrophil infiltration, ultimately inflammation, and tissue injury (53), thus establishing its requirement for kidney injury following IRI. In another, more recent study, researchers have identified a murine population of bone marrow neutrophils that constitutively express the transcription factor $\mathrm{ROR} \gamma \mathrm{t}$, and that rapidly produce and respond to IL-17A in a IL23 plus IL-6-dependent manner (54). Autocrine activity of IL-17A on such neutrophil subset has been shown not only to induce the production of reactive oxygen species (ROS), but also to increase neutrophil-mediated fungal killing in vitro and, importantly, also in an in vivo model of Aspergillus fumigatus-induced keratitis (55). In a similar fashion, IL-17A produced by $\mathrm{Ly} 6 \mathrm{G}^{+}$-neutrophils, but not by NKT or $\gamma \delta \mathrm{T}$ cells, was found to be important in providing protection against early pneumonic plague infection in mice (56). In this model, however, neutrophil-derived IL-17A did not significantly change neutrophil bactericidal activities, but was instead crucial for the IFN $\gamma$-mediated programming of M1 proinflammatory macrophages after Yersinia pestis challenge (56).

A number of in vivo experiments have reported that, in response to a variety of pathogens, including Nocardia asteroides (57), Listeria monocytogenes (58), and Plasmodium berghei (59), murine neutrophils secrete IFN $\gamma$, a crucial orchestrator for host defense against intracellular pathogen. Neutrophils have been found to be an important source of IFN $\gamma$ also upon Toxoplasma gondii infection, in a model of genetically modified mice lacking all lymphoid cells due to deficiencies in Recombination Activating Gene 2 (RAG2) and IL-2R $\gamma$ c genes (60). In these mice, although insufficient for complete host protection, neutrophil-derived IFN $\gamma$ was found to be TLR11-independent and to significantly reduce pathogen load therefore extending mice survival (60). Moreover, other studies have shown that migrated neutrophils are responsible for the early production of IFN $\gamma$ during pneumonia infections, in turn regulating bacterial clearance in mice (61). Interestingly, such IFN $\gamma$ production does not require either IL-12, or CD11/18 complex, CD44, TLR2, TLR4, TRIF, and Nrf2, while it is nearly abolished in Nox2 deficient mice (62). Altogether, data not only underline the complexity of the neutrophil responses during pneumonia, but also highlight how tightly regulated is the process of IFN $\gamma$ induction in neutrophils, as it likely involves interactions between multiple signaling pathways.

\section{TNF-SUPERFAMILY MEMBERS}

Human and murine neutrophils also express and produce many TNF-superfamily members (Figure 1A,B), although at variable levels (2). For example, human neutrophils synthesize - at least in vitro - very low amounts of $\mathrm{TNF} \alpha$ (in the order of picogram per milliliter per million cells) in response to TLR agonists (2), which nonetheless exert potent autocrine effects in amplifying neutrophil-derived cytokines and chemokines [(63) and other unpublished observations from our group]. In vivo, neutrophilderived $\mathrm{TNF} \alpha$ has been recently described to either instruct skin Langerhans cells to prime antiviral immune responses (64), or to stimulate melanoma cells to migrate towards endothelial cells and metastasize to the lungs, in a mouse model of primary cutaneous melanoma undergoing repetitive ultraviolet (UV) exposure (65). Moreover, through application of confocal intravital microscopy to the mouse cremaster muscle, it has been very recently shown that chemoattractans-responding neutrophils release TNF $\alpha$ when in close proximity of endothelial cell junctions. Further, in TNF receptor (TNFR) (-/-) mice, neutrophils accumulated normally in response to chemoattractants administered to the cremaster muscle or dorsal skin, whereas neutrophil-dependent plasma protein leakage was abolished, suggesting that neutrophil-derived $\mathrm{TNF} \alpha$ mediates microvascular leakage (66).

On the other hand, neutrophils have turned-out as a major source of both BAFF (67) and a proliferation inducing ligand (APRIL) (68), two TNF members that are critical for Bcell maturation, function, and survival. Accordingly, BAFF and APRIL (other than IL-21 and, possibly, CD40L) have proven to be fundamental mediators of the functions of a recently identified neutrophil subset in human spleen - the so called "Bhelper" neutrophil subset - precisely for their ability to stimulate immunoglobulin diversification and production by splenic marginal zone B-cells (69). An involvement of BAFF-producing splenic neutrophils in the pathogenesis of murine lupus has been also demonstrated in a recent study, suggesting that neutrophils help to shape $\mathrm{CD}^{+}{ }^{+} \mathrm{T}$ cell responses via BAFF, which in turn contributes to the production of pathogenic autoantibodies (70).

Finally, another TNF-superfamily member that both human and murine activated neutrophils can produce and release is TRAIL, a trans-membrane/soluble molecule involved in tumor cell killing and autoimmunity (33). In humans, neutrophilderived TRAIL has been classically detected ex vivo in the context of intravesical BCG infusion and systemic IFN $\alpha$ administration to treat, respectively, bladder cancer and chronic myeloid leukemia $(71,72)$. Since previous in vitro data had shown an effective TRAIL-mediated cytotoxicity of neutrophils towards leukemic cells $(73,74)$, it is conceivable to hypothesize further studies aimed at harnessing neutrophils against tumors, possibly via TRAIL induction. Nonetheless, our knowledge on the TRAIL production by neutrophils has been more recently extended to the mouse 
system, as neutrophil-derived TRAIL has been shown to exert antiviral activities in a model of cytomegalovirus infection (75), as well as to mediate early bacterial killing in a model of pneumococcal pneumonia (76). Based on the afore-mentioned and other $(2,8,42,43)$ observations, it appears that TNF-superfamily members may contribute to a large extent to unexpected functions that neutrophils may exert.

\section{CONCLUDING REMARIS}

During the past decades, novel functions in homeostasis and pathology have emerged for neutrophils, mainly for their ability to represent a source for a variety of cytokines. It is plausible that with the development of very efficient cell isolation techniques and the increased availability of neutrophils purified from various compartments, such as spleen, peritoneal exudates, lungs, oral cavity, skin, bone marrow, cord blood, and placenta, our knowledge of the repertoire of cytokines produced by human and mouse neutrophils will expand.

Apart from what has been briefly summarized in this review, a number of issues remain to be better explored and/or clarified in this research area.

For instance, we need to elucidate all the stimuli that are able to induce cytokine synthesis in neutrophils. Such studies would be particularly helpful in understanding the pathogenesis of diseases in which neutrophils represent (or are presumed to be) the first cell type encountering, and interacting with, the etiologic agent. In fact, we know that the interaction of neutrophils with a given agonist produces a characteristic, stimulus-specific response (2). The recent findings that human neutrophils possess intracellular sensor systems that allow the recognition of foreign and potentially dangerous RNA and DNA, as well as the inflammasomes $(17,77-80)$, demonstrates that neutrophils, via cytokine/chemokine release, are in the position to act at the front-line of immunity not only toward extracellular, but also toward intracellular microorganisms, including viruses. Another aspect that needs to be more systematically dissected concerns the identification of the molecular mechanisms controlling cytokine expression in neutrophils. Such studies may lead to the identification of novel, maybe neutrophilspecific, transcription factors, or of neutrophil-specific chromatin organization programs (36). Finally, more information on the in vivo role of neutrophil-derived cytokines should be acquired in humans, since it mostly derives from experimental animal models. By doing so, it is tempting to predict that unanticipated functions of neutrophils can be discovered. Future challenges for scientists in the field will be to translate all these new insights into efficacious neutrophil-targeted therapies for the treatment of inflammatory conditions without compromising immunity.

\section{ACKNOWLEDGMENTS}

This work was supported by grants from Associazione Italiana per la Ricerca sul Cancro (AIRC, IG-11782) to Marco A. Cassatella, and from Alessandro Moretti Foundation, Lions Club (San Giovanni Lupatoto, Zevio e destra Adige, Verona) to Cristina Tecchio. We are grateful to Patrizia Scapini for her critical reading of this manuscript. Alessandra Micheletti is a recipient of an AIRC fellowship.

\section{REFERENCES}

1. Feldmann M. Many cytokines are very useful therapeutic targets in disease. JClin Invest (2008) 118:3533-6. doi:10.1172/JCI37346

2. Cassatella MA. Neutrophil-derived proteins: selling cytokines by the pound. $A d v$ Immunol (1999) 73:369-509. doi:10.1016/S0065-2776(08)60791-9

3. Mócsai A. Diverse novel functions of neutrophils in immunity, inflammation, and beyond. J Exp Med (2013) 210:1283-1129. doi:10.1084/jem.20122220

4. Jaillon S, Galdiero MR, Del Prete D, Cassatella MA, Garlanda C, Mantovani A. Neutrophils in innate and adaptive immunity. Semin Immunopathol (2013) 35:377-94. doi:10.1007/s00281-013-0374-8

5. Mayadas TN, Cullere X, Lowell CA. The multifaceted functions of neutrophils. Annu Rev Pathol (2014) 9:181-218. doi:10.1146/annurev-pathol020712-164023

6. Tecchio C, Cassatella MA. Neutrophil-derived cytokines involved in physiological and pathological angiogenesis. Chem Immunol Allergy (2014) 99:123-37. doi:10.1159/000353358

7. Mantovani A, Cassatella MA, Costantini C, Jaillon S. Neutrophils in the activation and regulation of innate and adaptive immunity. Nat Rev Immunol (2011) 11:519-31. doi:10.1038/nri3024

8. Tecchio C, Scapini P, Pizzolo G, Cassatella MA. On the cytokines produced by human neutrophils in tumors. Semin Cancer Biol (2013) 23:159-70. doi:10. 1016/j.semcancer.2013.02.004

9. Tamassia N, Cassatella MA, Bazzoni F. Fast and accurate quantitative analysis of cytokine gene expression in human neutrophils. Methods Mol Biol (2014) 1124:451-67. doi:10.1007/978-1-62703-845-4_27

10. Scapini P, Calzetti F, Cassatella MA. On the detection of neutrophil-derived vascular endothelial growth factor (VEGF). J Immunol Methods (1999) 232:121-9. doi:10.1016/S0022-1759(99)00170-2

11. Pelletier M, Maggi L, Micheletti A, Lazzeri E, Tamassia N, Costantini C, et al. Evidence for a cross-talk between human neutrophils and Th17 cells. Blood (2010) 115:335-43. doi:10.1182/blood-2009-04-216085

12. Davey MS, Tamassia N, Rossato M, Bazzoni F, Calzetti F, Bruderek K, et al. Failure to detect production of IL-10 by activated human neutrophils. Nat Immunol (2011) 12:1017-8. doi:10.1038/ni.2111

13. Zhang X, Majlessi L, Deriaud E, Leclerc C, Lo-Man R. Coactivation of Syk kinase and MyD88 adaptor protein pathways by bacteria promotes regulatory properties of neutrophils. Immunity (2009) 31:761-71. doi:10.1016/j.immuni. 2009.09.016

14. Benelli R, Morini M, Carrozzino F, Ferrari N, Minghelli S, Santi L, et al. Neutrophils as a key cellular target for angiostatin: implications for regulation of angiogenesis and inflammation. FASEB J (2002) 16:267-9.

15. Thomas CJ, Schroder K. Pattern recognition receptor function in neutrophils. Trends Immunol (2013) 34:317-28. doi:10.1016/j.it.2013.02.008

16. Hayashi F, Means TK, Luster AD. Toll-like receptors stimulate human neutrophil function. Blood (2003) 102:2660-9. doi:10.1182/blood-2003-04-1078

17. Tamassia N, Le Moigne V, Rossato M, Donini M, McCartney S, Calzetti F, et al. Activation of an immunoregulatory and antiviral gene expression program in poly(I:C)-transfected human neutrophils. J Immunol (2008) 181:6563-73. doi:10.4049/jimmunol.181.9.6563

18. Janke M, Poth J, Wimmenauer V, Giese T, Coch C, Barchet W, et al. Selective and direct activation of human neutrophils but not eosinophils by Toll-like receptor 8. J Allergy Clin Immunol (2009) 123:1026-33. doi:10.1016/j.jaci.2009.02.015

19. Charmoy M, Megnekou R, Allenbach C, Zweifel C, Perez C, Monnat K, et al. Leishmania major induces distinct neutrophil phenotypes in mice that are resistant or susceptible to infection. J Leukoc Biol (2007) 82:288-99. doi:10.1189/jlb.0706440

20. Wang JP, Bowen GN, Padden C, Cerny A, Finberg RW, Newburger PE, et al. Toll-like receptor-mediated activation of neutrophils by influenza A virus. Blood (2008) 112:2028-34. doi:10.1182/blood-2008-01-132860

21. Matsushima H, Geng S, Lu R, Okamoto T, Yao Y, Mayuzumi N, et al. Neutrophil differentiation into a unique hybrid population exhibiting dual phenotype and functionality of neutrophils and dendritic cells. Blood (2013) 121:1677-89. doi:10.1182/blood-2012-07-445189

22. Tsuda Y, Takahashi H, Kobayashi M, Hanafusa T, Herndon DN, Suzuki F. Three different neutrophil subsets exhibited in mice with different susceptibilities to infection by methicillin-resistant Staphylococcus aureus. Immunity (2004) 21:215-26. doi:10.1016/j.immuni.2004.07.006

23. Tamassia N, Le Moigne V, Calzetti F, Donini M, Gasperini S, Ear T, et al. The MyD88-independent pathway is not mobilized in human neutrophils stimulated via TLR4. J Immunol (2007) 178:7344-56. doi:10.4049/jimmunol.178.11.7344 
24. van Bruggen R, Drewniak A, Tool AT, Jansen M, van Houdt M, Geissler J, et al. Toll-like receptor responses in IRAK-4-deficient neutrophils. J Innate Immun (2010) 2:280-7. doi:10.1159/000268288

25. Cassatella MA, Guasparri I, Ceska M, Bazzoni F, Rossi F. Interferon-gamma inhibits interleukin-8 production by human polymorphonuclear leucocytes. Immunology (1993) 78:177-84.

26. Meda L, Gasperini S, Ceska M, Cassatella MA. Modulation of proinflammatory cytokine release from human polymorphonuclear leukocytes by gamma interferon. Cell Immunol (1994) 157:448-61. doi:10.1006/cimm.1994.1241

27. Bazzoni F, Tamassia N, Rossato M, Cassatella MA. Understanding the molecular mechanisms of the multifaceted IL-10-mediated anti-inflammatory response: lessons from neutrophils. Eur J Immunol (2010) 40:2360-8. doi:10.1002/eji. 200940294

28. Cassatella MA. Cytokines Produced by Polymorphonuclear Neutrophils: Molecular and Biological Aspects. Berlin, Heidelberg, New York: Springer, Landes Co., (1996).

29. Bazzoni F, Rossato M, Fabbri M, Gaudiosi D, Mirolo M, Mori L, et al. Induction and regulatory function of miR-9 in human monocytes and neutrophils exposed to proinflammatory signals. Proc Natl Acad Sci U S A (2009) 106:5282-2587. doi:10.1073/pnas.0810909106

30. Dorhoi A, Iannaccone M, Farinacci M, Faé KC, Schreiber J, Moura-Alves P, et al. MicroRNA-223 controls susceptibility to tuberculosis by regulating lung neutrophil recruitment. J Clin Invest (2013) 123:4836-48. doi:10.1172/JCI67604

31. Lowe DM, Redford PS, Wilkinson RJ, O'Garra A, Martineau AR. Neutrophils in tuberculosis: friend or foe? Trends Immunol (2012) 33:14-25. doi:10.1016/j.it. 2011.10.003

32. Scapini P, Bazzoni F, Cassatella MA. Regulation of B-cell-activating factor (BAFF)/B lymphocyte stimulator (BLyS) expression in human neutrophils. Immunol Lett (2008) 116:1-6. doi:10.1016/j.imlet.2007.11.009

33. Cassatella MA. On the production of TNF-related apoptosis-inducing ligand (TRAIL/Apo-2L) by human neutrophils. J Leukoc Biol (2006) 79:1140-9. doi:10.1189/jlb.1005558

34. Lacy P, Stow JL. Cytokine release from innate immune cells: association with diverse membrane trafficking pathways. Blood (2011) 118:9-18. doi:10.1182/ blood-2010-08-265892

35. Mestas J, Hughes CC. Of mice and not men: differences between mouse and human immunology. J Immunol (2004) 172:2731-8. doi:10.4049/jimmunol. 172.5.2731

36. Tamassia N, Zimmermann M, Castellucci M, Ostuni R, Bruderek K, Schilling $\mathrm{B}$, et al. Cutting edge: an inactive chromatin configuration at the IL-10 locus in human neutrophils. J Immunol (2013) 190:1921-5. doi:10.4049/jimmunol. 1203022

37. Scapini P, Lapinet-Vera JA, Gasperini S, Calzetti F, Bazzoni F, Cassatella MA. The neutrophil as a cellular source of chemokines. Immunol Rev (2000) 177:195-203. doi:10.1034/j.1600-065X.2000.17706.x

38. Zlotnik A, Yoshie O. The chemokine superfamily revisited. Immunity (2012) 36:705-16. doi:10.1016/j.immuni.2012.05.008

39. Sadik CD, Kim ND, Luster AD. Neutrophils cascading their way to inflammation. Trends Immunol (2011) 32:452-60. doi:10.1016/j.it.2011.06.008

40. Scapini P, Cassatella MA. Social networking of human neutrophils within the immune system. Blood (2014) 124:710-9. doi:10.1182/blood-2014-03-453217

41. Codolo G, Bossi F, Durigutto P, Bella CD, Fischetti F, Amedei A, et al. Orchestration of inflammation and adaptive immunity in Borrelia burgdorferi-induced arthritis by neutrophil-activating protein A. Arthritis Rheum (2013) 65:1232-42. doi:10.1002/art.37875

42. Scapini P, Laudanna C, Pinardi C, Allavena P, Mantovani A, Sozzani S, et al. Neutrophils produce biologically active macrophage inflammatory protein-3alpha (MIP-3alpha)/CCL20 and MIP-3beta/CCL19. Eur J Immunol (2001) 31:1981-8.

43. Charmoy M, Brunner-Agten S, Aebischer D, Auderset F, Launois P, Milon G, et al. Neutrophil-derived CCL3 is essential for the rapid recruitment of dendritic cells to the site of Leishmania major inoculation in resistant mice. PLoS Pathog (2010) 6:e1000755. doi:10.1371/journal.ppat.1000755

44. Bennouna S, Bliss SK, Curiel TJ, Denkers EY. Cross-talk in the innate immune system: neutrophils instruct recruitment and activation of dendritic cells during microbial infection. J Immunol (2003) 171:6052-8. doi:10.4049/jimmunol.171. 11.6052

45. von Stebut E, Metz M, Milon G, Knop J, Maurer M. Early macrophage influx to sites of cutaneous granuloma formation is dependent on MIP-1alpha/beta released from neutrophils recruited by mast cell-derived TNFalpha. Blood (2003) 101:210-5. doi:10.1182/blood-2002-03-0921

46. Hagemann UB, Gunnarsson L, Géraudie S, Scheffler U, Griep RA, Reiersen H, et al. Fully human antagonistic antibodies against CCR4 potently inhibit cell signaling and chemotaxis. PLoS One (2014) 9:e103776. doi:10.1371/journal.pone. 0103776

47. Adib-Conquy M, Pedron T, Petit-Bertron AF, Tabary O, Corvol H, Jacquot J, et al. Neutrophils in cystic fibrosis display a distinct gene expression pattern. Mol Med (2008) 14:36-44. doi:10.2119/2007-00081.Adib-Conquy

48. Tsuda Y, Fukui H, Asai A, Fukunishi S, Miyaji K, Fujiwara S, et al. An immunosuppressive subtype of neutrophils identified in patients with hepatocellular carcinoma. J Clin Biochem Nutr (2012) 51:204-12. doi:10.3164/jcbn.12-32

49. Mishalian I, Bayuh R, Eruslanov E, Michaeli J, Levy L, Zolotarov L, et al. Neutrophils recruit regulatory T-cells into tumors via secretion of CCL17 - a new mechanism of impaired antitumor immunity. Int J Cancer (2014) 135:1178-86. doi:10.1002/ijc. 28770

50. Hoshino A, Nagao T, Nagi-Miura N, Ohno N, Yasuhara M, Yamamoto K, et al. MPO-ANCA induces IL-17 production by activated neutrophils in vitro via classical complement pathway-dependent manner. J Autoimmun (2008) 31:79-89. doi:10.1016/j.jaut.2008.03.006

51. Ethuin F, Gérard B, Benna JE, Boutten A, Gougereot-Pocidalo MA, Jacob $\mathrm{L}$, et al. Human neutrophils produce interferon gamma upon stimulation by interleukin-12. Lab Invest (2004) 84:1363-71. doi:10.1038/labinvest.3700148

52. Pelletier M, Micheletti A, Cassatella MA. Modulation of human neutrophil survival and antigen expression by activated CD4+ and CD8+ T cells. J Leukoc Biol (2010) 88:1163-70. doi:10.1189/jlb.0310172

53. Li L, Huang L, Vergis AL, Ye H, Bajwa A, Narayan V, et al. IL-17 produced by neutrophils regulates IFN-gamma-mediated neutrophil migration in mouse kidney ischemia-reperfusion injury. J Clin Invest (2010) 120:331-42. doi:10.1172/JCI38702

54. Taylor PR, Roy S, Leal SM Jr, Sun Y, Howell SJ, Cobb BA, et al. Activation of neutrophils by autocrine IL-17A-IL-17RC interactions during fungal infection is regulated by IL-6, IL-23, ROR $\gamma \mathrm{t}$ and dectin-2. Nat Immunol (2014) 15:143-51. doi: $10.1038 /$ ni.2797

55. Taylor PR, Leal SM Jr, Sun Y, Pearlman E. Aspergillus and Fusarium corneal infections are regulated by Th17 cells and IL-17-producing neutrophils. J Immunol (2014) 192:3319-27. doi:10.4049/jimmunol.1302235

56. Bi Y, Zhou J, Yang H, Wang X, Zhang X, Wang Q, et al. IL-17A produced by neutrophils protects against pneumonic plague through orchestrating IFN- $\gamma$ activated macrophage programming. J Immunol (2014) 192:704-13. doi:10. 4049/jimmunol.1301687

57. Ellis TN, Beaman BL. Murine polymorphonuclear neutrophils produce interferon-gamma in response to pulmonary infection with Nocardia asteroides. J Leukoc Biol (2002) 72:373-81.

58. Yin J, Ferguson TA. Identification of an IFN-gamma-producing neutrophil early in the response to Listeria monocytogenes. J Immunol (2009) 182:7069-73. doi:10.4049/Jimmunol.0802410

59. Chen L, Sendo F. Cytokine and chemokine mRNA expression in neutrophils from CBA/NSlc mice infected with Plasmodium berghei ANKA that induces experimental cerebral malaria. Parasitol Int (2001) 50:139-43. doi:10.1016/ S1383-5769(01)00063-0

60. Sturge CR, Benson A, Raetz M, Wilhelm CL, Mirpuri J, Vitetta ES, et al. TLR-independent neutrophil-derived IFN- $\gamma$ is important for host resistance to intracellular pathogens. Proc Natl Acad Sci U S A (2013) 110:10711-6. doi:10.1073/pnas.1307868110

61. Yamada M, Gomez JC, Chugh PE, Lowell CA, Dinauer MC, Dittmer DP, et al. Interferon- $\gamma$ production by neutrophils during bacterial pneumonia in mice. Am J Respir Crit Care Med (2011) 183:1391-401. doi:10.1164/rccm.201004$0592 \mathrm{OC}$

62. Gomez JC, Yamada M, Martin JR, Dang H, Brickey WJ, Bergmeier W, et al. Mechanisms of IFN- $\gamma$ Production by Neutrophils and Its Function during $S$. pneumoniae Pneumonia. Am J Respir Cell Mol Biol (2014). doi:10.1165/rcmb. 2013-0316OC

63. Cassatella MA, Meda L, Bonora S, Ceska M, Constantin G. Interleukin 10 (IL-10) inhibits the release of proinflammatory cytokines from human polymorphonuclear leukocytes. Evidence for an autocrine role of tumor necrosis factor and IL- 1 beta in mediating the production of IL- 8 triggered by lipopolysaccharide. $J$ Exp Med (1993) 178:2207-11. doi:10.1084/jem.178.6.2207 
64. Epaulard O, Adam L, Poux C, Zurawski G, Salabert N, Rosenbaum P, et al. Macrophage- and neutrophil-derived TNF- $\alpha$ instructs skin Langerhans cells to prime antiviral immune responses. JImmunol (2014) 193:2416-26. doi:10.4049/ jimmunol.1303339

65. Bald T, Quast T, Landsberg J, Rogava M, Glodde N, Lopez-Ramos D, et al. Ultraviolet-radiation-induced inflammation promotes angiotropism and metastasis in melanoma. Nature (2014) 507:109-13. doi:10.1038/ nature 13111

66. Finsterbusch M, Voisin MB, Beyrau M, Williams TJ, Nourshargh S. Neutrophils recruited by chemoattractants in vivo induce microvascular plasma protein leakage through secretion of TNF. J Exp Med (2014) 211:1307-14. doi:10.1084/jem.20132413

67. Scapini P, Nardelli B, Nadali G, Calzetti F, Pizzolo G, Montecucco C, et al. GCSF-stimulated neutrophils are a prominent source of functional BLyS. J Exp Med (2003) 197:297-302. doi:10.1084/jem.20021343

68. Mhawech-Fauceglia P, Kaya G, Sauter G, McKee T, Donze O, Schwaller J, et al. The source of APRIL up-regulation in human solid tumor lesions. J Leukoc Biol (2006) 80:697-704. doi:10.1189/jlb.1105655

69. Puga I, Cols M, Barra CM, He B, Cassis L, Gentile M, et al. B cell-helper neutrophils stimulate the diversification and production of immunoglobulin in the marginal zone of the spleen. Nat Immunol (2011) 13:170-80. doi:10.1038/ni.2194

70. Coquery CM, Wade NS, Loo WM, Kinchen JM, Cox KM, Jiang C, et al. Neutrophils contribute to excess serum BAFF levels and promote CD4+ T cell and B cell responses in lupus-prone mice. PLoS One (2014) 9:e102284. doi:10.1371/journal.pone.0102284

71. Brincks EL, Risk MC, Griffith TS. PMN and anti-tumor immunity - the case of bladder cancer immunotherapy. Semin Cancer Biol (2013) 23:183-9. doi:10.1016/j.semcancer.2013.02.002

72. Tanaka H, Ito T, Kyo T, Kimura A. Treatment with IFNalpha in vivo upregulates serum-soluble TNF-related apoptosis inducing ligand (sTRAIL) levels and TRAIL mRNA expressions in neutrophils in chronic myelogenous leukemia patients. Eur J Haematol (2007) 78:389-98. doi:10.1111/j.1600-0609. 2007.00834.x

73. Koga Y, Matsuzaki A, Suminoe A, Hattori H, Hara T. Neutrophil-derived TNFrelated apoptosis-inducing ligand (TRAIL): a novel mechanism of antitumor effect by neutrophils. Cancer Res (2004) 64:1037-43. doi:10.1158/0008-5472. CAN-03- 1808

74. Tecchio C, Huber V, Scapini P, Calzetti F, Margotto D, Todeschini G, et al. IFNalpha-stimulated neutrophils and monocytes release a soluble form of TNFrelated apoptosis-inducing ligand (TRAIL/Apo-2 ligand) displaying apoptotic activity on leukemic cells. Blood (2004) 103:3837-44. doi:10.1182/blood-200308-2806

75. Stacey MA, Marsden M, Pham NTA, Clare S, Dolton G, Stack G, et al. Neutrophils recruited by IL-22 in peripheral tissues function as TRAIL-dependent antiviral effectors against MCMV. Cell Host Microbe (2014) 15:471-83. doi:10. 1016/j.chom.2014.03.003

76. Steinwede K, Henken S, Bohling J, Maus R, Ueberberg B, Brumshagen C, et al. TNF-related apoptosis-inducing ligand (TRAIL) exerts therapeutic efficacy for the treatment of pneumococcal pneumonia in mice. J Exp Med (2012) 209:1937-52. doi:10.1084/jem.20120983

77. Tamassia N, Bazzoni F, Le Moigne V, Calzetti F, Masala C, Grisendi G, et al. IFN- $\beta$ expression is directly activated in human neutrophils transfected with plasmid DNA and is further increased via TLR-4-mediated signaling. J Immunol (2012) 189:1500-9. doi:10.4049/jimmunol.1102985

78. Berger M, Hsieh CY, Bakele M, Marcos V, Rieber N, Kormann M, et al. Neutrophils express distinct RNA receptors in a non-canonical way. J Biol Chem (2012) 287:19409-17. doi:10.1074/jbc.M112.353557

79. Tamassia N, Cassatella MA. Cytoplasmic receptors recognizing nucleic acids and mediating immune functions in neutrophils. Curr Opin Pharmacol (2013) 13:547-54. doi:10.1016/j.coph.2013.05.003

80. Bakele M, Joos M, Burdi S, Allgaier N, Pöschel S, Fehrenbacher B, et al. Localization and functionality of the inflammasome in neutrophils. J Biol Chem (2014) 289:5320-9. doi:10.1074/jbc.M113.505636

Conflict of Interest Statement: The authors declare that the research was conducted in the absence of any commercial or financial relationships that could be construed as a potential conflict of interest.

Received: 18 August 2014; accepted: 29 September 2014; published online: 21 October 2014.

Citation: Tecchio C, Micheletti A and Cassatella MA (2014) Neutrophilderived cytokines: facts beyond expression. Front. Immunol. 5:508. doi: 10.3389/fimmu.2014.00508

This article was submitted to Molecular Innate Immunity, a section of the journal Frontiers in Immunology.

Copyright () 2014 Tecchio, Micheletti and Cassatella. This is an open-access article distributed under the terms of the Creative Commons Attribution License (CC BY). The use, distribution or reproduction in other forums is permitted, provided the original author(s) or licensor are credited and that the original publication in this journal is cited, in accordance with accepted academic practice. No use, distribution or reproduction is permitted which does not comply with these terms. 